\title{
Applicability of day-to-day variation in behavior for the automated detection of lameness in dairy cows
}

\author{
R. M. de Mol, ${ }^{1}$ G. André, E. J. B. Bleumer, J. T. N. van der Werf, Y. de Haas, and C. G. van Reenen \\ Wageningen UR Livestock Research, PO Box 65, 8200 AB Lelystad, the Netherlands
}

\section{ABSTRACT}

Lameness is a major problem in modern dairy husbandry and has welfare implications and other negative consequences. The behavior of dairy cows is influenced by lameness. Automated lameness detection can, among other methods, be based on day-to-day variation in animal behavior. Activity sensors that measure lying time, number of lying bouts, and other parameters were used to record behavior per cow per day. The objective of this research was to develop and validate a lameness detection model based on daily activity data. Besides the activity data, milking data and data from the computerized concentrate feeders were available as input data. Locomotion scores were available as reference data. Data from up to 100 cows collected at an experimental farm during $23 \mathrm{mo}$ in 2010 and 2011 were available for model development. Behavior is cow-dependent, and therefore quadratic trend models were fitted with a dynamic linear model on-line per cow for 7 activity variables and 2 other variables (milk yield per day and concentrate leftovers per day). It is assumed that lameness develops gradually; therefore, a lameness alert was given when the linear trend in 2 or more of the 9 models differed significantly from zero in a direction that corresponded with lameness symptoms. The developed model was validated during the first 4 mo of 2012 with almost 100 cows on the same farm by generating lameness alerts each week. Performance on the model validation data set was comparable with performance on the model development data set. The overall sensitivity (percentage of detected lameness cases) was $85.5 \%$ combined with specificity (percentage of nonlame cow-days that were not alerted) of $88.8 \%$. All variables contributed to this performance. These results indicate that automated lameness detection based on day-to-day variation in behavior is a useful tool for dairy management.

Key words: detection model, activity, lameness, dynamic linear model

Received October 24, 2012.

Accepted February 16, 2013.

${ }^{1}$ Corresponding author: rudi.demol@wur.nl

\section{INTRODUCTION}

Lameness is among the main health problems in modern dairy herds (Kossaibati and Esslemont, 1997). With increasing farm size, the available time per cow for observation of abnormalities will decrease, which will affect the early diagnosis of lameness. Making use of sensor data might support the farmer in his daily management.

Behavior of dairy cows is influenced by lameness. High lying times, long lying bouts, and variability in the duration of lying bouts were associated with lameness by Ito et al. (2010). Lame cows spend more time lying out of the cubicles, have longer total lying times, and spend less time feeding (Galindo and Broom, 2002). Cows with ulcers spend more time lying down because of longer lying bouts (Chapinal et al., 2009, 2010). Lameness causes changes in behavior. The frequency that dairy cows visit an automated milking system (AMS) is related to their locomotory ability, and data from the AMS may help in early detection of lameness (Borderas et al., 2008).

Apart from the welfare implications, lameness in dairy cows has other negative consequences. Milk production of lame cows is lower (Bach et al., 2007), which appears to be caused by decreased feed intake and a decreased number of visits to the AMS. Test-day records were used by Archer et al. (2010) to show that cows that had been severely lame had a lower 305 -d milk yield. In general, lameness reduces milk production, feed intake, and fertility and is costly for producers (Flower and Weary, 2009).

Changes in cow behavior can be used in automated lameness monitoring. A detection model can be based on level changes in behavior variables if activity data are available. Automated detection might help the farmer detect all lameness cases and to receive earlier warnings, making appropriate treatment possible. The objective of this research was to develop and validate a detection model for lameness based on daily activity data.

\section{MATERIALS AND METHODS}

\section{Animals and Housing}

The study was carried out on the experimental dairy farm of Wageningen UR Livestock Research in Leeu- 
warden, the Netherlands. The dairy herd comprised 110 lactating Holstein cows split into 2 production groups containing, on average, 60 and 50 cows. Annual milk production averaged $9,530 \mathrm{~kg} / \mathrm{cow}$-year with $4.49 \%$ fat and $3.55 \%$ protein. Each group was housed in a separate part of a freestall barn with individual cubicles. The first group had a slatted floor and mattresses in the cubicles and the second group had a grooved floor and mats in the cubicles. EThere was 1 AMS per group (DeLaval, Steenwijk, the Netherlands). A cow was allowed to visit the AMS freely and she was milked when the interval since the previous milking was long enough: $8 \mathrm{~h}$ for first-lactation cows (resulting in 2 or 3 milkings per day) and at most $6 \mathrm{~h}$ for older cows (at least 4 milkings per day). The cows were fed roughage ad libitum and rationed concentrates. The roughage was supplied twice daily in the barn and was a mixture of grass silage, fodder corn, wheat yeast concentrate, straw, and minerals. The concentrates were supplied both in the AMS and by computerized concentrate feeders. The amount of concentrates allowed was set per cow and per day with the help of a tool that sets the rations based on the individual responses (André et al., 2011). Drinking water was available ad libitum.

\section{Collection of Input Data}

Data from the activity sensors, the AMS, and the concentrate feeder were available as input data for the lameness detection model. Input data were collected during 2010, 2011, and the first 4 mo of 2012. Only data after February 1, 2010, were used in the analysis, as the activity data were unreliable in the first month. The data collected in 2010 and 2011 were used for model development (model development data set); the data collected in 2012 were used to validate the lameness detection model (model validation data set).

Activity was recorded with 3 -dimensional accelerometers at $4 \mathrm{~Hz}$ (IceQubes sensors from IceRobotics, Edinburgh, UK). One hundred IceQubes were available for this research. An IceQube was attached to the fetlock joint of the left or right rear leg of a cow. Cows received an IceQube when they were introduced into 1 of the 2 production groups after calving. The IceQubes remained attached as long as the cow was in the production group; they were only removed when cows left the group (e.g., drying off) and they were replaced when the IceQube no longer functioned. Activity data were transmitted to a local server every time the cow passed a trigger point in front of the AMS. The data were then uploaded to an online data management system. The IceQube determined continuously whether a cow was lying or standing, as well as the number of steps taken. These data were used to derive the lying and standing bouts of a cow. For the current research, we decided to use only the aggregated data per cow and per day: lying time (proportion of day); standing time (proportion of day); number of lying bouts; number of standing bouts; maximum length of lying bout (proportion of day); minimal length of lying bout (proportion of day); maximum length of standing bout (proportion of day); minimal length of standing bout (proportion of day); motion index (an indication of the overall activity of the cow calculated using the acceleration on each of the 3 axes); and number of steps.

The lying and standing time, as well as the lying and standing bouts, were given as proportion of day, resulting in a value between 0 and 1 (e.g., a lying bout of 3 $\mathrm{h}$ corresponded to a value of $0.125 ; 3 / 24)$. The number of recorded visits to the AMS was divided into milkings or refusals. If a cow was milked, the milk yield of the quarter milk was recorded in kilograms. In this study, the milk yield used as an input trait was the sum of the quarterly milk yields. The amount of concentrates allowed and amount left over were recorded as kilograms per cow and per station (AMS or concentrate feeder). In general, cows prefer to consume their allowed concentrates and leftovers can indicate a disorder.

\section{Preprocessing of Input Data}

Part of the collected input data for the lameness detection model was preprocessed and another part was omitted. Preprocessing the input data was done to make the data more applicable; for example, milk yield per milking was transformed to milk yield per day. Quantile-quantile (Q-Q) plots (generated with the statistical package GenStat, VSN International Ltd., Hemel Hempstead, UK) were used to check whether the activity data followed a normal distribution. From this analysis, it was decided to use the base-10 logarithm for most of the activity data.

Some input data that did not have an added value were skipped; for example, lying time and standing time always sum to 1 , so only lying time was used as an input. A principal component analysis showed that all remaining activity variables did have an added value although they were sometimes related. The following data were used, after preprocessing, as inputs for the detection model: lying time (not preprocessed); number of lying bouts (not preprocessed); logarithm of maximum length of lying bout; logarithm of average lying bout (defined as lying time divided by number of lying bouts); logarithm of maximum length of standing bout; logarithm of average standing bout (defined as standing time divided by number of standing bouts); logarithm of number of steps; daily milk yield (derived from the cumulative milk yield at each milking and cut off at 
$0000 \mathrm{~h}$ ); and concentrate leftovers per day, aggregated over the feeding stations.

\section{Model Formulation}

The lameness detection model used the preprocessed data as input and generated lameness alerts as output. To make this possible, the behavior of cows was modeled based on activity and other variables. This was done per cow, as behavior is cow-dependent (Ito et al., 2009). Within-animal comparison allows the researcher to use the animal as its own control and thus avoid variation due to the animal factors described above (Flower and Weary, 2009). Once a cow-dependent model was available, the lameness alerts could be based on a gradual change in behavior related to lameness; for example, increased lying time.

The model used to describe the normal behavior reflected the fact that the behavior on successive days was related but might change over time. Quadratic trend models were used, where the variable shows a certain level that is changing in the course of time due to a linear trend and a quadratic trend:

$$
\begin{gathered}
Y_{t}=\mu_{t}+\nu_{t}, \\
\mu_{t}=\mu_{t-1}+\alpha_{t-1}+\beta_{t-1}+\omega_{1 t}, \\
\alpha_{t}=\alpha_{t-1}+\beta_{t-1}+\omega_{2 t}, \\
\beta_{t}=\beta_{t-1}+\omega_{3 t},
\end{gathered}
$$

where $Y_{t}=$ observed variable; $\mu_{t}=$ level at time $t ; \alpha_{t}=$ linear trend at time $t ; \beta_{t}=$ quadratic trend at time $t ; \nu_{t}$ $=$ observational error; and $\omega_{i t}=$ system error $(i=1,2$, $3)$. The parameters in the quadratic trend model were time-dependent to reflect that they might change with time. This quadratic trend model was used for all 7 activity variables, daily milk yield, and the concentrate leftovers.

The values of the parameters in the quadratic trend model should be known to be able to use the model for detection purposes, therefore the parameters were fitted on-line with a dynamic linear model (DLM). For the application of a DLM, a formulation with an observation equation and a system equation was needed (West and Harrison, 1997). The observation equation was

$$
\mathbf{Y}_{t}=\mathbf{F}_{t}^{\prime} \boldsymbol{\theta}_{t}+\boldsymbol{\nu}_{t}, \boldsymbol{\nu}_{t} \sim N\left[0, \mathbf{V}_{t}\right]
$$

where $\mathbf{Y}_{t}=$ observation vector - the measurement of the system (in the current application, the observed variable); $\boldsymbol{\theta}_{t}=$ state vector - the state of the system; here applied $\boldsymbol{\theta}_{t}=\left(\begin{array}{lll}\mu_{t} & \alpha_{t} & \beta_{t}\end{array}\right)^{\mathrm{T}}$, the parameters level, linear and quadratic trend defined the state that was fitted with the DLM; $\mathbf{F}_{t}=$ design matrix, which describes the relation between the state and the observation; in our case $\mathbf{F}_{t}=\left(\begin{array}{lll}1 & 0 & 0\end{array}\right)^{\mathrm{T}}$, this definition of the design matrix and the state vector in [5] indicate that level was observed, ignoring the observation error; $\boldsymbol{\nu}_{i}$ $=$ observational error, distributed normally with zero average and variance $\mathbf{V}_{t}$.

The system equation was

$$
\boldsymbol{\theta}_{t}=\mathbf{G}_{t} \boldsymbol{\theta}_{t-1}+\boldsymbol{\omega}_{t}, \boldsymbol{\omega}_{t} \sim N\left[0, \mathbf{W}_{t}\right],
$$

where $\mathbf{G}_{t}=$ system matrix, describing the relation between the current state and the previous state $t-1$; in our case, $\mathbf{G}_{t}=(1,1,1 ; 0,1,1 ; 0,0,1)$; the system matrix was independent of cow and day; $\boldsymbol{\omega}_{t}=$ system error, distributed normally with zero average and variance $\mathbf{W}_{t}$.

This DLM was applied for every cow $c$ and every day $t$. Discount factors were used to model the decay of information from the past; West and Harrison (1997) recommend values between 0.8 and 1.0. In the current application, the chosen value of the discount factors was 0.9 for the parameters and 0.99 for the variance. In case of an outlier, the used discount factors were lower (0.8 and 0.975$)$, allowing the system to adapt faster to possible changes in the system.

These definitions made it possible to estimate the state, and thus the parameter values, of the system on-line. The implementation was based on West and Harrison (1997) and as described in André et al. (2011). It resulted in estimates of the parameter values and the covariance between them. André et al. (2011) noted that the discrepancy between forecast and observation was judged by the Bayes factor, expressing the likelihood that the observation fitted into the actual routinely used model relative to an alternative and exceptional outlier model with an observation variance 3 times higher. When the Bayes factor was lower than a threshold, the observation was classified as a potential outlier. In the current application, the outliers were interpreted as deviating values of the variables that did not fit in the normal behavioral pattern.

\section{Generation of Lameness Alerts}

The output of the lameness detection model consisted of alerts for lameness indicating that a cow might suffer from lameness on the current day. Lameness alerts should correspond with changing behavior related to lameness. These changes occur in the behavior-describ- 
combined lameness alert were classified as false positive (FP); other nonlame days were classified as true negative $(\mathbf{T N})$. Each lameness case was either TP or FN; the detection performance for lame cows was expressed in the sensitivity: $\mathrm{TP} /(\mathrm{TP}+\mathrm{FN})$. Each nonlame cowday was either $\mathrm{FP}$ or $\mathrm{TN}$; the detection performance for healthy cows was expressed in the specificity: TN/ $(\mathrm{TN}+\mathrm{FP})$.

To illustrate this procedure, an example of the classification of a lameness case and nonlame days is given in Figure 1, where the locomotion scores and combined lameness alerts in the first lactation of cow 938 are presented. Eleven locomotion scores were available for this cow, 9 with a score of 1 (nonlame), and 2 scores equal to 3 (lame), on April 17 and 19, 2012 (d 838 and 840 from January 1, 2010). According to our definitions, this cow was lame on d 838 when the locomotion score was 3 and the previous score was 1 . This case was classified as TP because 13 combined lameness alerts occurred in the period from d 825 to 838 . The level of these 13 alerts varied between 2 and 5 . The cow was nonlame in the period from d 713 until 825, and alerts

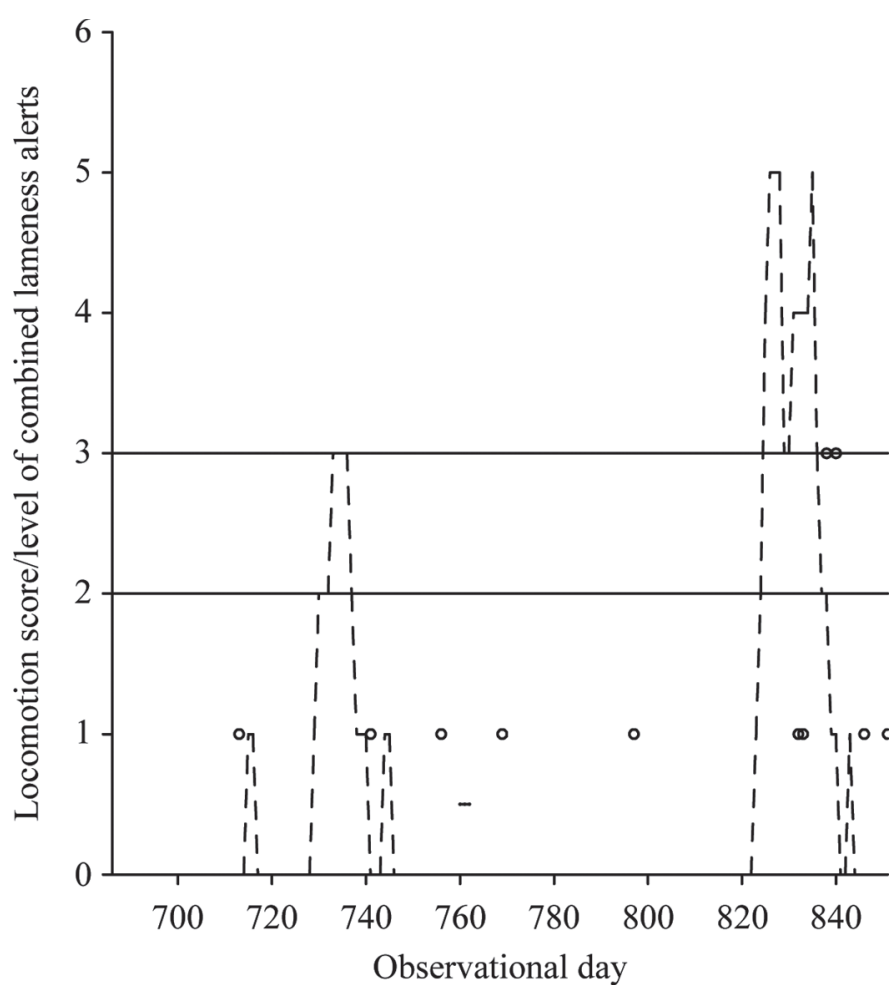

Figure 1. Locomotion scores $(\bigcirc)$ and combined lameness alerts $(---)$ of cow 938 in the period from calving on November 16, 2011 (d 685 since January 1, 2010) until the end of the experiment on April 30, 2012 (d 851). The upper horizontal line represents the threshold for lameness cases and the lower horizontal line represents the threshold for combined lameness alerts. The small dots at level 0.5 represent days without activity data. in this period were classified as FP; FP alerts were given on $\mathrm{d} 734$ to 736 . The days before the first known locomotion score on d 713 were not considered in the analysis.

\section{Indeterminable Lameness Cases and Nonlame Days}

The performance of the lameness detection model was influenced by the performance of the sensors for activity, milk yield, and concentrates intake. A lameness case cannot be detected with a detection model based on activity data when there are no activity sensor measurements. Cases with insufficient sensor data were called indeterminable. If problems occurred with an IceQube, all activity data were missing for that cow and day. There were no occurrences when the value of one activity variable (e.g., lying time) was known and another (e.g., number of steps) was missing.

A lameness case was defined to be indeterminable when any of the following 3 situations occurred: (1) the percentage of days without activity data in the period since the preceding locomotion score was 50\% or more (if the length of this period was $<14 \mathrm{~d}$, then a 14 -d period was considered); (2) the percentage of days without activity data in the preceding week was $50 \%$ or more; or (3) more than one day without activity data occurred in the period consisting of the day when locomotion was scored and the 2 preceding days.

A day in a nonlame period was indeterminable when the activity data were missing on that day. Indeterminable cases were not included in the calculation of the sensitivity, and indeterminable days were not included in the calculation of the specificity.

The number of attached IceQubes per day and the number of valid activity measurements per day are shown in Figure 2. The performance of the activity sensors was suboptimal. On several occasions, cows lost their activity sensors or the activity sensors stopped working. Therefore, the number of attached activity sensors could be $<100$. In some cases, it was also not possible to collect the activity data of an attached sensor because of poor performance of the system. Therefore, the number of valid activity measurements could be (much) lower than the number of attached sensors. To counteract these problems, all sensors were renewed 3 times during the experimental period.

Problems were also encountered in recording of milk yield and concentrates intake, but these were less frequent and had only minor influence on the results.

\section{Model Validation Procedure}

The detection model was developed using the model development data set and performance was determined. 


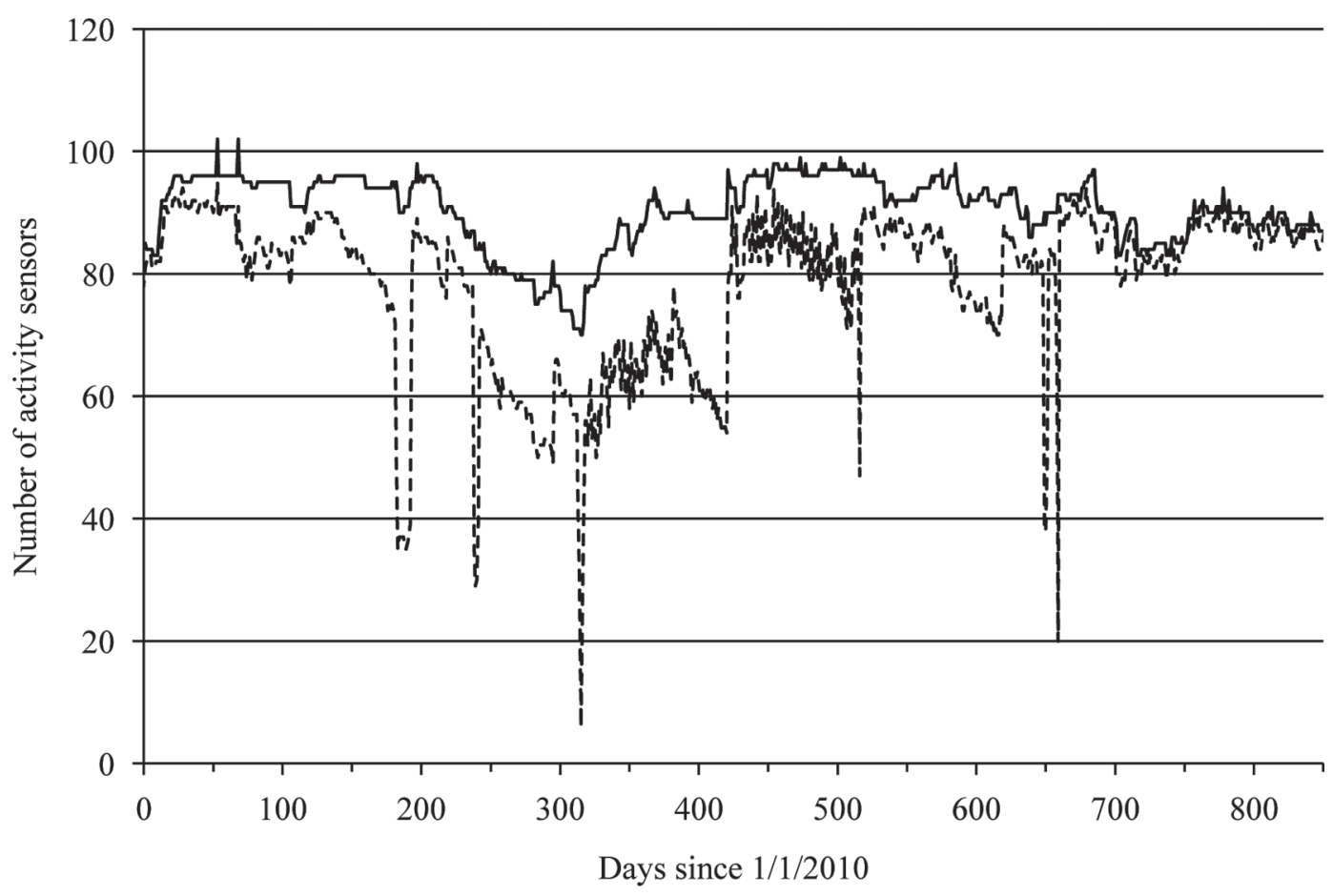

Figure 2. Number of attached activity sensors (- ${ }_{-}$) and number of valid activity measurements $(---)$in the experiment shown per day from January 1, 2010 (January 1, $2010=\mathrm{d}$ 1, April 30, $2012=\mathrm{d}$ 851).

The performance on the model validation data set might be a better indicator because it was not used for model development. Model validation was performed in the first 4 mo of 2012. A list of alerts was generated weekly on every Tuesday that included the lameness alerts of the preceding Tuesday until Monday. The alerts on the list were checked as if they were available daily. To achieve this, the data from the farm were collected every Tuesday morning and transferred to the proper data format. Dynamic linear models were used to fit the model parameters. A list of combined lameness alerts was generated and transformed to a userfriendly alerts report. This alerts report was sent to the farm on Tuesday afternoon, and the alerts were checked by a farm worker on Wednesday. Each cow with one or more lameness alerts was scored for locomotion (in addition to the regular locomotion scoring); the new locomotion score was added to the alerts report. These findings were added to the alerts report and the annotated alerts report was returned on Thursday.

\section{RESULTS}

\section{Model Development Data Set}

The global results of the lameness detection model over the period from February 1, 2010, to December 31, 2011, are presented in the upper parts of Tables 2 and
3. The performance problems of the activity sensor are reflected in the number of indeterminable cases (17). Out of the 68 determinable cases, 59 were detected by the model, resulting in a sensitivity of $86.8 \%$ (Table 2 ). Each combined lameness alert was a combination of at least 2 variables with a lameness alert, as defined in Table 1. The average level was 3.5, indicating that, on average, more than 3 variables contributed to the lameness alerts. A TP case had, on average, 7.1 alerts.

The data set included 5,271 indeterminable nonlame cow-days, which was $13 \%$ of all nonlame cow-days. The remaining 35,187 determinable nonlame cow-days were either FP or TN, resulting in a specificity of $88.5 \%$ (Table 3). The level of a FP alert was, on average, 2.5.

The contribution of each variable to the combined lameness alerts was investigated by calculating the number of TP cases and the number of FP cow-days for each variable (Table 4). A lameness alert per variable was only included in the results of Table 4 when it was part of a combined lameness alert. The data set included 68 determinable cases, of which 59 cases had one or more combined lameness alerts. All activity variables contributed substantially to this result. Maximum length of lying bout was the lowest contributor (26 out of 68) and number of lying bouts the highest (47). The other 2 variables, milk yield and concentrate leftovers, showed lower but still positive contributions. 
Table 2. Classification of lameness cases and sensitivity (\% of TP cases) for the model development data set (February 1, 2010, until December 31, 2011), the model validation set (January 1, 2012, to April 30, 2012), and the combined data set

\begin{tabular}{lclc}
\hline Data set & $\begin{array}{c}\text { No. of } \\
\text { lameness cases }\end{array}$ & $\begin{array}{l}\text { Determinability (classification) } \\
\text { of lameness cases }\end{array}$ & Sensitivity (\%) \\
\hline Model development & 85 & $\begin{array}{l}68 \text { determinable (59 TP, 9 FN) } \\
17 \text { indeterminable }\end{array}$ & 86.8 \\
Model validation & 15 & $\begin{array}{l}15 \text { determinable (12 TP, 3 FN) } \\
0 \text { indeterminable }\end{array}$ & 80.0 \\
Combined & 100 & 83 determinable (71 TP, 12 FN) & 85.5 \\
& 17 indeterminable & \\
\hline
\end{tabular}

${ }^{1}$ Each determinable lameness case was classified as either true positive (TP) or false negative (FN).

Of the 35,187 determinable nonlame cow-days, 4,029 had an FP combined lameness alert. Again, all activity variables contributed to this result, with maximum length of lying bout as the lowest contributor (482) and number of lying bouts as the highest $(3,164)$.

\section{Model Validation Data Set}

Model validation in 2012 lasted 17 wk; on average, 16 cows had a lameness alert on one or more days at the weekly alerts report. The performance of the lameness detection model during this period is presented in the middle parts of Tables 2 and 3. The data set included 15 determinable lameness cases, of which 12 were detected. The sensitivity was $80.0 \%$ (Table 2), which was lower than the sensitivity over $2010-2011$ (86.8\%). The significance of this difference was tested by assuming a binomial distribution with probability of success 0.868 . The probability of 12 or fewer successes out of 15 was $48.3 \%$, and the difference was, therefore, not significant. The average level of the TP cases was 3.5 and, on average, there were 5.7 alerts. From the results in Table 3 , it follows that the specificity was $89.9 \%$, which was higher than the specificity over 2010-2011. The average level of the FP alerts was 2.5.

\section{DISCUSSION}

The performance of the lameness detection model on the model development data set was comparable to that on the model validation data set. This is to be expected because the model is adaptive in nature and does not use any characteristics of the data set. This might imply that the combined performance on both data sets would be indicative of the model's practical performance in similar dairy housing systems. The results of the combined data set are presented in the lower parts of Tables 2 and 3. Over the whole period, 71 of 83 determinable lameness cases were detected (sensitivity $85.5 \%$ ), and 38,325 of the 43,157 determinable nonlame cow-days were TN (specificity $88.8 \%$ ). However, although the results presented here might be representative for cows housed in a loose housing system and milked in an AMS, the model should be validated in other housing systems; for example, to examine the effects of grazing or other milking and feeding systems.

The availability and performance of the sensors was not always optimal. The results in Figure 2 indicate that the number of cows with activity data was often less than the expected number (100). The combined data set encompassed $820 \mathrm{~d}$, so if all 100 IceQubes had

Table 3. Classification of nonlame cow-days and specificity (\% of TN nonlame cow-days) for the model development data set (February 1, 2010, to December 31, 2011), the model validation set (January 1, 2012, to April 30, 2012), and the combined data set

\begin{tabular}{lccc}
\hline Data set & $\begin{array}{c}\text { No. of } \\
\text { nonlame } \\
\text { cow-days }\end{array}$ & $\begin{array}{l}\text { Determinability (classification) } \\
\text { of nonlame cow-days }\end{array}$ & Specificity $(\%)$ \\
\hline Model development & 40,458 & $\begin{array}{l}35,187 \text { determinable }(31,158 \mathrm{TN}, 4,029 \mathrm{FP}) \\
5,271 \text { indeterminable }\end{array}$ & 88.5 \\
Model validation & 8,145 & $\begin{array}{l}7,970 \text { determinable }(7,167 \mathrm{TN}, 803 \mathrm{FP}) \\
175 \text { indeterminable }\end{array}$ & 89.9 \\
Combined & 49,665 & $\begin{array}{l}44,189 \text { determinable }(39,294 \mathrm{TN}, 4,895 \mathrm{FP}) \\
5,476 \text { indeterminable }\end{array}$ & 88.9 \\
\hline
\end{tabular}

${ }^{1}$ Each determinable nonlame cow-day was classified as either true negative (TN) or false positive (FP) 
Table 4. Number of true positive (TP) cases and false positive (FP) cow-days per variable contributing to the combined lameness alerts of the detection model over the period from February 1, 2010, to December 31, 2011 (upper parts of Tables 2 and 3 )

\begin{tabular}{lcc}
\hline Variable & $\begin{array}{c}\text { TP cases } \\
\text { (out of 68 determinable } \\
\text { lameness cases) }\end{array}$ & $\begin{array}{c}\text { FP cow-days } \\
\text { (out of 35,187 determinable } \\
\text { nonlame cow-days) }\end{array}$ \\
\hline Lying time & 39 & 1,233 \\
Number of lying bouts & 47 & 3,164 \\
Maximum length of lying bout & 26 & 482 \\
Average length of lying bout & 30 & 1,400 \\
Maximum length of standing bout & 31 & 843 \\
Average length of standing bout & 41 & 1,719 \\
Number of steps & 38 & 877 \\
Daily milk yield & 4 & 227 \\
Concentrate leftovers & 16 & 236 \\
\hline
\end{tabular}

performed perfectly, we would have 82,000 cow-days. However, the combined data set included 73,811 cowdays $(90 \%)$, of which 64,040 cows-days $(78 \%)$ had valid activity measurements. The number of attached IceQubes was lower because of hardware problems and the number of activity measurements could be lower than the number of attached sensors because of transmission or software problems. This suboptimal performance resulted in a considerable number of indeterminable cases and cow-days in our experiment, particularly in the model development data set (Tables 2 and 3). The detection results on determinable cases and cow-days were influenced by missing data, and we expect that detection performance would increase if sensor performance increases. The performance of the sensors was adequate for the model validation data set (beginning on d 730 after January 1, 2010), indicating that the quality of the sensor system had improved considerably.

It should be noted that lameness was apparently not a serious problem in this dairy herd. A lameness case was defined as a cow having a locomotion score $\geq 3$. The combined data sets included 100 lameness cases. The number of lameness cases for other thresholds of the locomotion score is given in Table 5. A threshold of 4 yielded 29 lameness cases and a threshold of 5 yielded only 1 . This means that the algorithm developed within the current project was able to detect relatively mild cases of lameness. This suggests that the current detection model could be useful in detecting early stages of lameness, before the occurrence of severe lameness, which would be important for prevention purposes. The sensitivity of the lameness detection algorithm was higher if only severe lameness cases (locomotion scores 4 or 5) were considered (Table 5).

The results for specificity were based on the inclusion of all FP alerts as if they were independent. Based on the structure of the detection model, it is known that FP alerts are not independent because they mostly occur in a sequence of FP days (as long as the appropriate linear trend is nonzero). The specificity could be improved by considering only the first alerts in a sequence. This has not been done because this would neglect information on the number of successive alerts and the level of alerts in such a sequence. Both characteristics might be helpful in judging the relevance of lameness alerts.

The results of the detection model depend on the settings in the DLM, especially the discount factors and the threshold for the Bayes factor. Higher discount factors increase the influence of previous measurements; lower discount factors decrease this influence and give the model more freedom for adaptation. A higher threshold

Table 5. Sensitivity (\%) for the combined data sets with varying thresholds for locomotion score to define a lameness case (with number of lameness cases) and required number of alerted variables for a combined lameness alert (with specificity) ${ }^{1}$

\begin{tabular}{|c|c|c|c|c|c|}
\hline \multirow[b]{2}{*}{ Item } & \multirow[b]{2}{*}{ Specificity $(\%)$} & \multicolumn{4}{|c|}{ Threshold for locomotion score to define a lameness case } \\
\hline & & 2 & 3 & 4 & 5 \\
\hline \multicolumn{6}{|l|}{ Required number of alerted variables } \\
\hline 1 & 68.4 & 94.4 & 98.8 & 100 & 100 \\
\hline 2 & 88.9 & 73.9 & 85.5 & 96.2 & 100 \\
\hline 3 & 96.1 & 42.2 & 59.0 & 73.1 & 100 \\
\hline
\end{tabular}

${ }^{1}$ Results for the default setting (2 alerted variables required) are shown in bold. 
for the Bayes factor would result in fewer alerts and, in general, lower sensitivity and higher specificity. This makes it possible to adapt the model performance to the needs of the end user: higher sensitivity with more FP alerts versus fewer FP alerts with lower sensitivity.

Another setting in the lameness detection model is the number of alerted variables required for a combined lameness alert. We set this number at 2 in the presented results; sensitivity and specificity for other numbers of required alerted variables are presented in Table 5. As can be seen, sensitivity decreases and specificity increases with an increased number of required alerted variables; which number is preferred will depend on the preferences of the user of the detection model. The number applied here (2) was chosen to have an acceptable balance between sensitivity and specificity.

A combined lameness alert was generated when there were 2 or more alerted variables. The level (the number of alerted variables) was not used in the weekly alerts report during the validation test because the combined alerts were presented as yes/no variables. It might have been better to include the level in the weekly alerts report, because the level is an indication of the significance of the changes in behavior. The average level of TP alerts was higher than the level of FP alerts, indicating that the probability that an alert is true was higher at a higher level. The level might help the end user in his or her decision on how to react on an alert; a farmer might skip alerts with a lower level. The preferred action of the farmer on a lameness alert is not always evident, and this is a subject for follow-up research.

In the current research, the reference data were based on locomotion scores. For practical reasons, the timescale of the locomotion scores differs from the timescale of the activity data. Scoring of locomotion is time consuming and it is not practical to do it very frequently. In this research, we decided to do locomotion scoring at least once a month. The results were based on the assumption that lameness cases develop over several days: if the score is 3 where the previous score was lower, then a lameness case with changing behavior developed gradually in this interval; if the score is 1 and the previous score was also 1 , then we assumed that the cow did not have locomotion problems in between. The method used is therefore not valid for lameness cases that develop rapidly.

Reference data for lameness can also be based on reported hoof treatments. The presence of foot lesions accounted for 20 to $70 \%$ of the variation in gait scores (Flower and Weary, 2009). The results of Dyer et al. (2007) showed that lateral claw pain was related to ipsilateral limb locomotion score. Detection performance may depend on type of hoof lesions: Flower and Weary
(2006) could discriminate healthy cows from cows with sole ulcers (with a numerical rating system) but not healthy cows from cows with sole hemorrhages. Thus, the relation between lameness and locomotion score is more straightforward, and therefore locomotion scores were used for reference data in the present study.

Automated lameness detection can also be based on the cow's locomotion or other activity measurements. Several methods have been studied in this respect: weighting individual legs with 4 platforms (e.g., Pastell et al., 2010), force plates (Liu et al., 2011), video image analysis (Poursaberi et al., 2010), pressure-sensitive walkways (Maertens et al., 2011), and activity sensors (Chapinal et al., 2009; Ito et al., 2010). In general, it is difficult to compare the results of these various approaches, not only because of differences in method, but also due to differences in reference data (hoof lesions or locomotion scores with different thresholds), number of cows involved, and experimental setup. However, the method presented here outperforms most other methods with regard to sensitivity and specificity.

The detection model as described here is restricted to lameness detection. Similar models have been developed for estrus and mastitis detection (de Mol et al., 2012). Estrus detection is based on outliers in the number of steps combined with outliers in other variables. Mastitis detection is based on outliers in electrical conductivity of quarter milk combined with outliers in other variables. de Mol et al. (2012) concluded that automated estrus and mastitis detection can be improved by applying data from the activity sensors. Thus, activity sensors are useful not only for lameness detection but also for estrus and mastitis detection.

\section{CONCLUSIONS}

We developed a lameness detection model based on detecting changes using a DLM in measured activity (and milk yield or concentrate leftovers). The results for the model development data set were similar to those of the model validation data set. The overall sensitivity of the model was $85.5 \%$, which makes the model worthwhile for application in practice. However, the overall specificity was $88.8 \%$, which may not be high enough for practice and should be improved first. Lameness detection based on changing behavior is a promising approach. The unreliable performance of the sensors made it difficult to collect activity data consistently; automated monitoring is only possible when the data collection system is functioning well.

\section{ACKNOWLEDGMENTS}

We acknowledge the assistance of IceRobotics (Edinburgh, UK) in the maintenance of the activity sensors 
system. The staff of Dairy Campus Leeuwarden (the Netherlands) is acknowledged for their efforts during this project. This project was funded by the Dutch Commodity Board for Dairy Products (Zoetermeer, the Netherlands) and the Dutch Ministry of Economic Affairs, Agriculture and Innovation (Den Haag, the Netherlands) with support from the "Smart Dairy Farming" research program.

\section{REFERENCES}

André, G., B. Engel, P. B. M. Berentsen, G. Van Duinkerken, and A. G. J. M. Oude Lansink. 2011. Adaptive models for online estimation of individual milk yield response to concentrate intake and milking interval length of dairy cows. J. Agric. Sci. 149:769-781.

Archer, S. C., M. J. Green, and J. N. Huxley. 2010. Association between milk yield and serial locomotion score assessments in UK dairy cows. J. Dairy Sci. 93:4045-4053.

Bach, A., M. Dinarés, M. Devant, and X. Carré. 2007. Associations between lameness and production, feeding and milking attendance of Holstein cows milked with an automatic milking system. J. Dairy Res. 74:40-46.

Borderas, T. F., A. Fournier, J. Rushen, and A. M. B. de Passillé. 2008. Effect of lameness on dairy cows' visits to automatic milking systems. Can. J. Anim. Sci. 88:1-8.

Chapinal, N., A. M. de Passillé, J. Rushen, and S. Wagner. 2010. Automated methods for detecting lameness and measuring analgesia in dairy cattle. J. Dairy Sci. 93:2007-2013.

Chapinal, N., A. M. de Passillé, D. M. Weary, M. A. G. von Keyserlingk, and J. Rushen. 2009. Using gait score, walking speed, and lying behavior to detect hoof lesions in dairy cows. J. Dairy Sci. 92:4365-4374.

de Mol, R. M., G. André, E. J. B. Bleumer, J. T. N. van der Werf, and C. G. van Reenen. 2012. Automated detection of lameness in dairy cows based on day-to-day variation in behaviour. Page 48 in Book of Abstracts of the Annual Meeting of the European Federation of Animal Science, Bratislava, Slovakia. Wageningen Academic Publishers, Wageningen, the Netherlands.
Dyer, R. M., N. K. Neerchal, U. Tasch, Y. Wu, P. Dyer, and P. G. Rajkondawar. 2007. Objective determination of claw pain and its relationship to limb locomotion score in dairy cattle. J. Dairy Sci. 90:4592-4602.

Flower, F. C., and D. M. Weary. 2006. Effect of hoof pathologies on subjective assessments of dairy cow gait. J. Dairy Sci. 89:139-146.

Flower, F. C., and D. M. Weary. 2009. Gait assessment in dairy cattle. Animal 3:87-95.

Galindo, F., and D. M. Broom. 2002. The effects of lameness on social and individual behavior of dairy cows. J. Appl. Anim. Welf. Sci. 5:193-201.

Ito, K., M. A. G. von Keyserlingk, S. J. LeBlanc, and D. M. Weary. 2010. Lying behavior as an indicator of lameness in dairy cows. J. Dairy Sci. 93:3553-3560.

Ito, K., D. M. Weary, and M. A. G. von Keyserlingk. 2009. Lying behavior: Assessing within- and between-herd variation in free-stallhoused dairy cows. J. Dairy Sci. 92:4412-4420.

Kossaibati, M. A., and R. J. Esslemont. 1997. The costs of production diseases in dairy herds in England. Vet. J. 154:41-51.

Liu, J., R. M. Dyer, N. K. Neerchal, U. Tasch, and P. G. Rajkondawar. 2011. Diversity in the magnitude of hind limb unloading occurs with similar forms of lameness in dairy cows. J. Dairy Res. $78: 168-177$.

Maertens, W., J. Vangeyte, J. Baert, A. Jantuan, K. C. Mertens, S. De Campeneere, A. Pluk, G. Opsomer, S. Van Weyenberg, and A. Van Nuffel. 2011. Development of a real time cow gait tracking and analysing tool to assess lameness using a pressure sensitive walkway: The GAITWISE system. Biosystems Eng. 110:29-39.

Pastell, M., L. Hänninen, A. M. de Passillé, and J. Rushen. 2010. Measures of weight distribution of dairy cows to detect lameness and the presence of hoof lesions. J. Dairy Sci. 93:954-960.

Poursaberi, A., C. Bahr, A. Pluk, A. Van Nuffel, and D. Berckmans. 2010. Real-time automatic lameness detection based on back posture extraction in dairy cattle: Shape analysis of cow with image processing techniques. Comput. Electron. Agric. 74:110-119.

West, M., and J. Harrison. 1997. Bayesian Forecasting and Dynamic Models. 2nd ed. Springer-Verlag, New York, NY.

Winckler, C., and S. Willen. 2001. The reliability and repeatability of a lameness scoring system for use as an indicator of welfare in dairy cattle. Acta Agric. Scand. A Anim. Sci. Suppl. 30:103-107. 